\title{
Belief into Action Scale: A Brief but Comprehensive Measure of Religious Commitment
}

\author{
Harold G. Koenig1,2,3,4*, Bruce Nelson', Sally F. Shaw5, Faten Al Zaben', Zhizhong Wang7, \\ Salil Saxena ${ }^{8}$ \\ ${ }^{1}$ Department of Psychiatry \& Behavioral Sciences, Duke University Medical Center, Durham, USA \\ ${ }^{2}$ Department of Medicine, Duke University Medical Center, Durham, USA \\ ${ }^{3}$ Department of Medicine, King Abdulaziz University, Jeddah, Saudi Arabia \\ ${ }^{4}$ School of Public Health, Ningxia Medical University, Yinchuan, China \\ ${ }^{5}$ Department of Research, Glendale Adventist Medical Center, Glendale, USA \\ ${ }^{6}$ Department of Psychiatry, King Abdulaziz University, Jeddah, Saudi Arabia \\ ${ }^{7}$ Department of Epidemiology and Statistics, School of Public Health, Ningxia Medical University, Yinchuan, \\ China \\ ${ }^{8}$ Center for Aging, Duke University, Durham, USA \\ Email: ${ }^{*}$ Harold.Koenig@duke.edu
}

Received 23 December 2014; accepted 19 January 2015; published 22 January 2015

Copyright (C) 2015 by authors and Scientific Research Publishing Inc.

This work is licensed under the Creative Commons Attribution International License (CC BY). http://creativecommons.org/licenses/by/4.0/

CC) (i) Open Access

\section{Abstract}

Objective: Our goal was to develop a comprehensive measure of religious involvement for those affiliated with monotheistic religious traditions that fully captures the centrality of religion in life. Methods: A convenience sample of female caregivers of those with chronic disabling illness, recruited from North Carolina and California, completed a questionnaire including a new 10-item scale called the Belief into Action (BIAC) scale (possible score range: 10 - 100). Psychometric properties of the BIAC were examined. Results: 231 participants completed the BIAC (87\% Christian). The average score was 46.3 (range: 10 - 90). Cronbach alpha was 0.89 (95\% CI $0.86-0.91$ ) and the intra-class correlation coefficient between two administrations $(n=60)$ was $0.919(95 \%$ CI 0.869 0.951). Convergent validity was demonstrated by high correlations between the BIAC and existing religiosity scales; divergent validity by weak correlations with mental, social, and physical health outcomes; construct validity by high correlations between individual items and total scale score (r's 0.58 - 0.80); factor analytic validity by a single factor that explained $94.4 \%$ of the scale's variance; and predictive validity by small to moderate correlations with psychosocial outcomes in expected directions. Conclusion: The BIAC is a reliable and valid scale for comprehensively assessing religious involvement in female caregivers affiliated with monotheistic religions, Christianity in particular. Psychometric properties of the scale need to be established in other populations.

\footnotetext{
${ }^{*}$ Corresponding author.
} 


\section{Keywords}

\section{Religion, Monotheism, Measurement, Psychometrics, Belief, Spirituality}

\section{Introduction}

There are many scales assessing religiosity or spirituality [1]. Why develop another one? Many of the existing measures assess religiosity in a relatively superficial manner, often consist of only a few items or limited response range, rely heavily on religious belief or attitude [2], or are contaminated by indicators of mental health [3]. Is the measurement of beliefs or attitudes alone sufficient to capture the form and depth of religiosity that is likely to influence health outcomes? For example, simply asking people about their belief in God may say very little about the depth or meaning that religious faith has in their lives. Indeed, there is a scripture that says: "Thou believest that there is one God; thou doest well: the devils also believe, and tremble" (James 2:19, KJV).

In response to this concern and the need to develop a measure capable of quantifying the full range of religious involvement, we developed a 10-item Belief into Action (BIAC) scale composed of new items and those from existing scales, and expanded response options to increase sensitivity and variability (i.e., 1 to 10 for each item with a total range from 10 to 100). The goal was to develop a measure that could clearly 1) discriminate between those who are not religious, those who are religious, and those who are deeply religious (whose lives center on their religious faith); and 2) capture the three major dimensions of religiosity in a comprehensive manner (i.e., subjective importance of religion in life, organizational or social religious activity, and non-organizational or private religious activity) [4].

First, then, we needed an item that identified what area of life the person most valued or considered of primary importance above all other priorities (i.e., the core of their motivation). In western monotheistic traditions (and to some extent in Eastern pantheistic traditions as well), the gold standard for this item-based on the sacred scriptures in these traditions-is a focus on the transcendent (i.e., God, Allah, Hashem, Brahman, Buddha, Ultimate Reality). In the Jewish Bible, the 1st commandment is: "I am HaShem thy G-d, who brought thee out of the land of Egypt, out of the house of bondage. Thou shalt have no other gods before Me" (Exodus 20:2-3, Jewish Publication Society Bible). In the New Testament, the "greatest commandment" according to Jesus was "Thou shalt love the Lord thy God with all thy heart, and with all thy soul, and with all thy mind" (Matthew 22:37, KJV) (repeated in three of the four gospels). In the Qur'an, there is little doubt that God is first and primary. The Islamic creed of belief (confession of faith) in Arabic begins with Là 'iläha 'illa Alläh ("There is no god but God") (Qur'an 3:18, Oxford World’s Classics), and the Muslim's duty is to surrender his or her life to God. In fact, the word "Islam" means surrender.

Rather than simply identify what a person says he or she truly values or considers most important in life, we felt there was need for evidence supporting such a claim. Conventional wisdom would suggest that whatever people spend their time and their money on is what they truly value, no matter what they actually say. For those who spend most of their free time with family, this indicates that family is what is really important to them (the same might be said for time spent with friends). For those who spend most of their free time investing in their business or work, this suggests that their work is what is really important to them. For those who spend most of their free time watching and playing sports, this suggests that sports is what they value the most. Time, indeed, is our most precious commodity and one that we dole out carefully on things that are most important to us. The same is true for what people spend money on. There is an old saying that says "look at your checkbook if you want to know what is important in your life." Because money is often limited, people tend to spend it only on things they really value, forgoing other possible sources of pleasure. Thus, if religion is a central part of a person's life, then there should be evidence for it in the way they spend their time and their money. Religion will have a cost to those who pursue it.

To address the points above, items for the BIAC scale were chosen-focused on monotheism- to assess 1) what a person truly prizes or values in life ("relationship with God" being one of many possible priorities); 2) the extent to which a person has consciously chosen to surrender life to God or otherwise conform life to their religious beliefs; 3) how much time within a 24-hour period is actually spent on religious activity (religious practices, including volunteering); and 4) what proportion of one's finances is given to support religious causes. 
Thus, the 10-item BIAC depends heavily on theoretical considerations and on the face validity of the items chosen.

In order to test the initial psychometric properties of the BIAC, we chose a sample of stressed female caregivers from the east and west coasts of the United States. First, we wanted persons who had a real need for religion in their lives as they grappled with difficult circumstances. Caregiving for a loved one with dementia, neurological illness, and other chronic disabling medical illness is known to be very stressful. Depression rates are high in this setting [5]-[8], and there are serious consequences for caregiver physical health as well [9]-[11]. For many of individuals, religious beliefs and practices give meaning to the caregiving role and surround the person with a supportive community that helps give strength to continue in that difficult and often isolating role. This has been widely documented in hundreds of qualitative and quantitative studies from around the world [12] [13], those in caregivers in particular [14]-[17]. Second, we chose female caregivers because women are more likely to be caregivers than men (70\% - 75\% of caregivers are women) [18] [19], and women generally tend to be more religious than men for a variety of reasons [20]. Third, we conducted this study in both North Carolina (part of the Bible belt) and in Los Angeles County, California (part of the multi-cultural, less conservative west coast), so that participants would have a wide range of religious beliefs and perspectives. We hypothesized that the BIAC scale would have solid psychometric properties in terms of both reliability and validity in this combined population.

\section{Methods}

A convenience sample was recruited from Durham County (central North Carolina) and Los Angeles County (southern California) between May 22, 2013 and August 1, 2014. Inclusion criteria were 1) female, 2) ages 40 to $75,3)$ primary family caregiver for a person with chronic disabling illness, and 4) significant disability in the cared-for person as indicated by the need for assistance in at least one of six physical activities of daily living (ADLs) (bathing, dressing, toileting, eating, walking, transferring) and at least three of eight instrumental ADLs (using telephone, shopping, preparing food, keeping house, doing laundry, traveling independently, taking own medications, handling finances). Participants were screened on the telephone and then arrangements were made for an in-person meeting to fill out a questionnaire that took approximately 30 - 45 minutes to complete. The questionnaire was self-explanatory and required only minimal assistance from the trained interviewers who administered it. Because caregivers often had to hire someone to watch over their family member during their absence, and had to pay for parking and travel expenses, participants were reimbursed $\$ 100$ for their time and effort. Those from the Durham County site who agreed to complete the BIAC a second time one week later were paid an additional \$20. The study was approved by the Duke University Medical Center institutional review board (protocol \#42861) and Glendale Adventist Medical Center ethics committee (1/16/14).

\subsection{Measures}

Demographic characteristics assessed included age, education, race/ethnicity, relationship to cared-for person, and duration of caregiving.

Perceived stress. Perceived stress includes feeling overwhelmed, stressed, or not having control over things, and was measured using the Perceived Stress Scale (PSS) [21]. The PSS consists of 10 statements rated by subjects from never (0) to very often (4), with a score range from 0 to 40 . The average stress score based on a 1983 Harris poll of a representative US sample of adult women was 13.7 (SD 6.6).

Caregiver burden. Caregiver burden includes embarrassment, overload, entrapment, resentment, isolation from society, loss of control, poor communication, and pressures from the physical work. The 22-item Zarit Burden Interview is the standard instrument in the field for measuring caregiver burden (score range 0 - 88), and assesses burden, stress, embarrassment, anger, fear, strain, suffering, isolation, expectations, financial strain, loss of control, uncertainty, and sense of adequacy in relationship to the caregiver role [22].

Depression. Depressive symptoms are an indirect measure of stress level and caregiver burden. The 20-item CES-D was used to assess this domain [23].

Physical health. Caregiver health was assessed using the 26-item OARS Comorbidity Scale [24]. The OARS scale identifies medical illnesses likely to be experienced by middle-aged and older adults and assesses the extent to which each illness interferes with physical activities, providing severity ratings for each of the 26 most common illnesses in this age group. The OARS scale was also used to assess the medical conditions of the 
cared-for person and the degree to which these interfered with physical activities. In addition, the disability level of the cared-for person was directly assessed by the Katz six-item measure of basic ADLs (physical activities of daily living) [25] and the Lawton eight-item measure of IADLs (instrumental activities of daily living) [26]. The OARS, Katz, and Lawton scales were rated by the caregiver for the cared-for person.

Social support. Social support was assessed with the 12-item Social Support Questionnaire [27]. This measure assesses the degree of social interaction (number of people nearby that one can depend on and feel close to) (6 items) and the subjective satisfaction with the support received (6 items).

Religious involvement. The primary religious variable for determining convergent validity was the 10 -item intrinsic religiosity (IR) scale [28]. Response options for each of the items range from 1 to 5 ("definitely not true" to "definitely true") creating a possible 10 - 50 score range. The scale has high internal reliability (Cronbach's alpha 0.87 , replicated in two separate populations), high test-retest reliability (91\% agreement after a six-week interval), and high validity (based on two studies involving ministers' judgments [28] [29]). IR reflects the degree to which religion is the object of a person's ultimate concern and is sought after as an end in itself, and represents a cognitive resource for providing hope and meaning to the caregiver role and reducing stress, depression, and burden.

Secondary religious variables for comparison with the BIAC assessed several other dimensions of religiosity: organizational religious activity (ORA), non-organizational religious activity (NORA), church-based support (CBS), and religious coping (RC). Religious attendance and church-based support (ORA) reflected the social dimension of religiosity that might help counteract caregiver isolation. NORA involved private religious resources mobilized to respond to the challenges of caregiving. ORA and NORA were measured using the first two items of the Duke University Religion Index, whose psychometric characteristics have been established in both community and clinical populations [30]. In addition, as a more specific measure of the support received from ORA, church-based social support was assessed using a 12-item scale [31] (range 12 - 48, average 41.0, based on data from 1998 General Social Survey), which is made up of subscales assessing emotional support received from one's congregation, emotional support provided to other members, anticipated future support from members if needed, and negative interactions with members. The latter subscale was scored in reverse when combining subscales to obtain a total religious support score. Finally, the 7-item negative religious coping (NRC) subscale of the brief RCOPE [32] was administered (score range 0 - 21) to assess religious struggles that caregivers might experience. This measure predicts an increased risk of mortality [33] and has been associated with higher pro-inflammatory cytokine levels [34].

\subsection{Statistical Analysis}

Descriptive statistics were used to determine the characteristics of the sample. Associations between the total BIAC score and demographic, caregiving, religious, psychosocial, and physical health characteristics were examined using Pearson correlations for continuous variables and analysis of variance or Student's t-test for comparison of continues variables across categorical variables. The reliability of the BIAC was determined using internal consistency and test-retest statistics. Internal reliability was assessed using the Cronbach alpha coefficient that was calculated for the overall 10-item BIAC scale and for the BIAC after each item was removed (to assess the contribution the item made to overall scale reliability) [35]. An alpha that is over 0.70 is considered satisfactory internal reliability. Test-retest reliability was determined using the Intra-class Correlation Coefficient (ICC) and Pearson correlation between the two administrations of the scale one week apart. The method used to determine the ICC for individual items on the BIAC and the overall scale has been described by Shrout and Fleiss $(2,1)$ random set [36]. An ICC of 0.70 or higher is considered acceptable.

Convergent validity of the BIAC was evaluated by calculating Pearson correlations between the BIAC and other measures of religiosity (intrinsic religiosity, religious support, negative religious coping, and religious affiliation). Divergent or discriminant validity was examined using the Pearson correlation between the BIAC and depressive symptoms, caregiver burden, number of persons in social network, and caregiver physical health. Construct validity was examined by the Pearson correlation between each item on the BIAC and the total BIAC scale score (r's $>0.40$ are considered acceptable). Factor analytic validity was determined using principal component analysis (PCA). In order to check the factorability of the correlation matrix, we used the Kaiser-MeyerOlkin (KMO) [37] measure of sampling adequacy (which should exceed 0.60) and Bartlett's test of sphericity [38] (which should be significant at $\mathrm{p}<0.05$ to reject the null hypothesis that the variables are not related to one 
another). PCA was conducted using the Kaiser-Guttman rule that states the number of factors to be extracted should be equal to the number of factors having an eigenvalue of greater than 1.0 [39]. SAS (version 9.3; SAS Institute Inc., Cary, North Carolina) was used for all analyses except when calculating the ICC and Cronbach's alpha (with confidence intervals) for which IBM SPSS Statistics, version 22, was used.

\section{Results}

A total of 251 caregivers completed the initial questionnaire (151 from Durham County and 100 from Los Angeles County) and 60 consecutive participants from the Durham site agreed to complete the BIAC a second time one week later (mean 6.7 days, SD = 1.1). Demographic, caregiver, religious, psychosocial and physical health characteristics of the sample are presented in Table 1. The average age of participants was 57.6 years; most had at least some college (average 14.8 years of education); and the majority were either white Caucasian (45.0\%) or Black (36.6\%). The most frequent medical condition of the cared-for person was dementia (35.9\%) (i.e., Alzheimer's disease or vacular dementia). In the majority of cases the caregiver was a child (49.6\%) or spouse (24.4\%) of the cared-for person, and the average duration of caregiving was just over six years (74.1 months). The vast majority of participants were Christian (86.7\%), although there were several Jewish, Muslim, and Buddhist participants, as well as those associated with a wide range of other religious groups (Bahai, Unitarian, Druid/Pagan, Science of Mind, etc.). Only a small percentage indicated no religious affiliation (3.3\%).

\subsection{BIAC Scale}

The BIAC scale was completed in less than 5 minutes by most participants and was easily understood regardless

Table 1. Characteristics of the sample $(n=251)$ and associations with BIAC scale score.

\begin{tabular}{|c|c|c|c|}
\hline Characteristic & $\%(n)$ & Mean (SD) (n) & BIAC $^{1}$ \\
\hline \multicolumn{4}{|l|}{ Demographic } \\
\hline Age, years (range 40 - 75) & & $57.6(8.6)(249)$ & $r=-0.02$ \\
\hline Education, years & & $14.8(3.5)(242)$ & $r=-0.02$ \\
\hline \multicolumn{4}{|l|}{ Race } \\
\hline White & $45.0(112)$ & & $38.9^{* * * *}$ \\
\hline Black & $36.6(91)$ & & 55.2 \\
\hline Hispanic & $8.4(21)$ & & 49.8 \\
\hline Asian & $7.2(19)$ & & 41.4 \\
\hline Other & $2.8(7)$ & & 47.4 \\
\hline \multicolumn{4}{|l|}{ Site } \\
\hline North Carolina & $60.2(151)$ & & 47.2 \\
\hline Los Angeles County & $39.8(100)$ & & 45.1 \\
\hline \multicolumn{4}{|l|}{ Caregiving } \\
\hline \multicolumn{4}{|l|}{ Relationship to cared-for person } \\
\hline Spouse or partner & $24.4(61)$ & & $38.8^{* *}$ \\
\hline Child & $49.6(124)$ & & 47.2 \\
\hline Parent & $9.2(23)$ & & 46.7 \\
\hline Other $1^{\text {st }}$ or $2^{\text {nd }}$ degree relative & $10.8(27)$ & & 56.6 \\
\hline Non-relative & $6.0(15)$ & & 53.1 \\
\hline Duration of caregiving (months) & & $74.1(80.1)(247)$ & $r=-0.06$ \\
\hline
\end{tabular}




\section{Continued}

\section{Religious}

Denomination

Christian

86.7 (212)

$49.8^{* * * * *}$

Jewish

2.5 (6)

20.2

Muslim

1.6 (3)

23.0

Buddhist

2.1 (5)

27.4

Other religion

3.7 (9)

33.0

3.3 (8)

13.3

Attendance at services $(1-6)$

Private religious activities (1 - 6)

Intrinsic religiosity (range 10 - 50)

Religious support (overall, 12 - 48)

Received (3 - 12)

Anticipated (3 - 12)

Provided (3 - 12)

Negative interaction (3 - 12)

Negative religious coping (range 0 - 21)

\section{$3.3(8)$}

\footnotetext{
Psychosocial

Social support

No. of supportive persons (0 - 54)

Satisfaction with support (6 - 36)

Caregiver depression (CESD) (0 - 60)

Caregiver burden (0 - 88)

Perceived stress (0 - 40)
}

\section{Physical health}

Caregiver illness/impairment (0 - 78)

Cared-for person illness/impairment (0 - 78)

Cared-for person ADL impairment (8 - 42)

$\begin{array}{lc}18.2(11.4)(251) & r=0.13^{*} \\ 31.4(6.1)(250) & r=0.30^{* * * * *} \\ 21.2(8.6)(251) & r=-0.12 \\ 40.9(16.3)(251) & r=-0.19^{* *} \\ 18.6(6.9)(251) & r=-0.24^{* * *}\end{array}$

$4.2(4.2)(251)$

$r=0.01$

11.9 (7.6) (251)

$r=-0.02$

$32.9(5.3)(251)$

${ }^{*} \mathrm{p}<0.05,{ }^{* *} \mathrm{p}<0.01,{ }^{* * *} \mathrm{p}<0.001,{ }^{* * * *} \mathrm{p}<0.0001 .{ }^{1}$ Pearson correlation (r) used to determine association between BIAC and continuous variables; Student's t-test or analysis of variance used to compare average BIAC scores across categorical variables. ADL = activities of daily living (physical and instrumental); CESD = Center for Epidemiologic Studies-Depression scale.

of race or education level. The average score on the scale was 46.3 (SD 20.7, range 10 to 90) (Table 2). There was no significant difference on the BIAC between North Carolina and California sites (47.2 vs. 45.1, p = ns). Highest scores were obtained on the question asking about extent to which person had decided to place their life under God's direction $(7.5, \mathrm{SD}=3.2)$ or had decided to conform life to religious teachings $(6.6, \mathrm{SD}=3.4)$, whereas the lowest score was obtained on the question asking about time spent on religious volunteering (2.6, $\mathrm{SD}=2.4)$.

Higher scores overall on the BIAC were obtained by Black Americans (55.2) and Hispanics (49.8), and the lowest score by white Caucasians (38.9) (Table 1). Interestingly, somewhat higher scores were obtained by relatives of the cared-for person other than spouse, child or parent (those who were perhaps less "expected" to serve 
in the caregiving role). Christians scored higher on the BIAC (49.8) than those with other religious affiliations (23.6) or no affiliation (13.3).

\subsection{Reliability}

Internal consistency of the BIAC overall, and after deleting each item of the scale to evaluate how removing the item influenced the scale's reliability, is displayed in Table 3. The BIAC scale had a Cronbach $\alpha$ coefficient of 0.89 (95\% CI 0.86 - 0.91), and deleting individual items from the scale had little effect on its reliability. Testretest reliability after one week was demonstrated by an ICC of 0.919 (95\% CI $0.869-0.951)$ for the overall scale; ICC's for individual items ranged from 0.566 to 0.970 (Table 4). Pearson correlations between the two times of administration were similar to ICCs.

Table 2. Items and average scores on the BIAC $(n=245)$.

\begin{tabular}{lc}
\hline & Mean (SD) \\
\hline BIAC1 (God highest priority in life now) & $3.9(4.2)$ \\
BIAC2 (frequency of religious attendance) & $5.6(2.8)$ \\
BIAC3 (religious social get-togethers besides attendance) & $4.5(3.0)$ \\
BIAC4 (decided to place life under God's direction) & $7.5(3.2)$ \\
BIAC5 (percent of annual income given to religious causes) & $4.6(2.8)$ \\
BIAC6 (time spent listening/viewing religious media) & $3.9(2.8)$ \\
BIAC7 (time spent reading religious scriptures, religious literature) & $3.5(2.2)$ \\
BIAC8 (time spent in prayer or meditation) & $3.8(2.1)$ \\
BIAC9 (time spent in religious volunteering) & $2.6(2.4)$ \\
BIAC10 (decided to conform life to religious teachings) & $6.6(3.4)$ \\
Total BIAC scale & $46.3(20.7)$ \\
\hline
\end{tabular}

Table 3. Reliability coefficients for the BIAC scale and for the scale after individual items deleted $(\mathrm{n}=245)$.

\begin{tabular}{|c|c|}
\hline & Alpha $^{1}(95 \%$ CI) \\
\hline Total BIAC scale & $0.89(0.86-0.91)$ \\
\hline \multicolumn{2}{|l|}{ Item removed } \\
\hline BIAC1 (God highest priority in life) & $0.89(0.87-0.91)$ \\
\hline BIAC2 (attendance at religious services) & $0.87(0.84-0.89)$ \\
\hline BIAC3 (religious get-togethers besides attendance) & $0.88(0.85-0.90)$ \\
\hline BIAC4 (place life under God’s direction) & $0.87(0.84-0.89)$ \\
\hline BIAC5 (percent of annual income given) & $0.87(0.85-0.89)$ \\
\hline BIAC6 (time spent listening/viewing religious media) & $0.88(0.85-0.90)$ \\
\hline BIAC7 (time spent reading religious scriptures, etc.) & $0.87(0.84-0.89)$ \\
\hline BIAC8 (time spent in prayer or meditation) & $0.88(0.85-0.90)$ \\
\hline BIAC9 (time spent in religious volunteering) & $0.88(0.86-0.90)$ \\
\hline BIAC10 (conform life to religious teachings) & $0.87(0.85-0.89)$ \\
\hline
\end{tabular}

${ }^{1}$ Cronbach's alpha (raw, not standardized) for total scale and for total scale with item removed. 
Table 4. Test-retest reliability for BIAC individual items and total score $(n=60)$.

\begin{tabular}{lcc}
\hline & ICC $(95 \%$ CI) & Pearson r \\
\hline BIAC1 (God highest priority) & $0.657(0.485-0.780)$ & 0.657 \\
BIAC2 (religious attendance) & $0.970(0.951-0.982)$ & 0.970 \\
BIAC3 (other religious social) & $0.673(0.507-0.791)$ & 0.673 \\
BIAC4 (life under God's direction) & $0.839(0.744-0.901)$ & 0.843 \\
BIAC5 (\% annual income given) & $0.891(0.823-0.933)$ & 0.892 \\
BIAC6 (viewing religious media) & $0.907(0.849-0.943)$ & 0.907 \\
BIAC7 (reading religious scripture) & $0.755(0.621-0.846)$ & 0.759 \\
BIAC8 (private prayer/meditation) & $0.566(0.366-0.716)$ & 0.576 \\
BIAC9 (religious volunteering) & $0.786(0.665-0.866)$ & 0.791 \\
BIAC10 (conform to religious teachings) & $0.859(0.774-0.913)$ & 0.862 \\
BIAC total & $0.919(0.869-0.951)$ & 0.919 \\
\hline
\end{tabular}

${ }^{1}$ ICC $=$ intra-class correlation coefficient.

\subsection{Validity}

As evidence for convergent validity, significant positive correlations were found between the BIAC scale score and intrinsic religiosity $(r=0.77)$, positive religious support subscales $(r=0.61-0.66)$, and a negative correlation was found with NRC as expected $(r=-0.20)$ (Table 1$)$. Those with a religious affiliation scored nearly four times higher on the BIAC (47.5, 95\% CI 44.9 - 50.1) than did those without a religious affiliation (13.3, 95\% CI 9.2 - 17.3). Not surprisingly, the BIAC was highly correlated with frequency of religious attendance $(r=0.76)$ and private religious activity $(r=0.60)$ since the BIAC contains question on religious attendance and private religious activity.

Divergent or discriminant validity was demonstrated by weak correlations between the BIAC and other psychological, social, and physical health constructs. These included depressive symptoms ( $r=-0.12$ with CESD), caregiver burden $(r=-0.19)$, number of persons in the caregiver's social support network $(r=0.13)$, and caregiver physical health $(r=0.01)$. Predictive validity, however, was indicated by stronger correlations with perceived stress $(r=-0.24)$ and satisfaction with support $(r=0.30)$, as expected given the stress buffering and supportive role that religious involvement may serve.

Finally, construct validity was indicated by high correlations between individual items on the BIAC and the BIAC total scores (Table 5), with r's ranging from 0.58 to 0.80 (all above 0.40 ), a finding supported by factor analysis. Factor analytic validity of the BIAC was examined using principal component analysis (PCA). The factorability of the correlation matrix was demonstrated by an acceptable KMO (0.90) and Bartlett's test of sphericity $\left(\chi^{2}=1173.3, \mathrm{p}<0.0001\right)$. PCA revealed only one factor with an eigenvalue 4.73 that explained $94.4 \%$ of the total variance of the scale, with factor loadings for individual items ranging from 0.545 to 0.797 (Table 6). The eigenvalue of the second largest factor was 0.44 (below the minimum value of 1.0 by the Kaiser-Guttman rule). The scree plot is presented in Figure 1.

\section{Discussion}

This study indicates that the BIAC is a theoretically sound scale and comprehensive measure of religious commitment and practice. Most participants were stressed family caregivers from the eastern and western United States, although there was surprisingly little difference in the average score between the two sites (47.2 vs. 45.1 on a scale from 10 to 100 ).

Both reliability and validity of the BIAC scale were demonstrated. The internal reliability was 0.89 (95\% CI 0.86 - 0.91), which is well above the acceptable level of 0.70 . Test-retest reliability after one week was also high (ICC $=0.92$, 95\% CI 0.87 - 0.95), again well above the minimum value of 0.70 . Construct validity was demonstrated by high correlations between individual items on the BIAC and the total scale score (r's ranging from 
Table 5. Correlation matrix of individual items of BIAC scale and total scale score $(n=245)$.

\begin{tabular}{|c|c|c|c|c|c|c|c|c|c|c|c|}
\hline & 1 & 2 & 3 & 4 & 5 & 6 & 7 & 8 & 9 & 10 & Total \\
\hline BIAC1 & 1.0 & & & & & & & & & & \\
\hline BIAC2 & 0.44 & 1.0 & & & & & & & & & \\
\hline BIAC3 & 0.34 & 0.59 & 1.0 & & & & & & & & \\
\hline BIAC4 & 0.45 & 0.57 & 0.47 & 1.0 & & & & & & & \\
\hline BIAC5 & 0.41 & 0.67 & 0.46 & 0.51 & 1.0 & & & & & & \\
\hline BIAC6 & 0.37 & 0.43 & 0.30 & 0.50 & 0.49 & 1.0 & & & & & \\
\hline BIAC7 & 0.47 & 0.57 & 0.52 & 0.54 & 0.53 & 0.59 & 1.0 & & & & \\
\hline BIAC8 & 0.32 & 0.46 & 0.44 & 0.47 & 0.37 & 0.49 & 0.64 & 1.0 & & & \\
\hline BIAC9 & 0.15 & 0.40 & 0.50 & 0.32 & 0.39 & 0.35 & 0.49 & 0.51 & 1.0 & & \\
\hline BIAC10 & 0.41 & 0.50 & 0.43 & 0.70 & 0.51 & 0.46 & 0.53 & 0.45 & 0.32 & 1.0 & \\
\hline Total BIAC & 0.65 & 0.78 & 0.70 & 0.78 & 0.74 & 0.69 & 0.80 & 0.68 & 0.58 & 0.75 & 1.0 \\
\hline
\end{tabular}

Pearson correlations.

Table 6. Factor loadings for individual items on factor 1 of BIAC scale $(\mathrm{N}=245)$.

\begin{tabular}{ll}
\hline & Factor 1 \\
\hline BIAC1 (God highest priority) & 0.545 \\
BIAC2 (religious attendance) & 0.762 \\
BIAC3 (other religious social) & 0.659 \\
BIAC4 (life under God's direction) & 0.751 \\
BIAC5 (\% annual income given) & 0.713 \\
BIAC6 (viewing religious media) & 0.651 \\
BIAC7 (reading religious scripture) & 0.797 \\
BIAC8 (private prayer/meditation) & 0.678 \\
BIAC9 (religious volunteering) & 0.561 \\
BIAC10 (conform to religious teachings) & 0.713 \\
Total variance explained & $94.4 \%$ \\
\hline
\end{tabular}

0.58 to 0.80 , all exceeding the minimum criterion of 0.40 ), as well as by the emergence of one factor that explained $94.4 \%$ of the scale variance, confirming that the BIAC scale measures a single underlying construct (religious commitment).

Discriminant and convergent validity, considered the most essential aspects of construct validity [40], were also demonstrated. There was evidence for discriminant validity by weak correlations between the BIAC and constructs such as mood $(r=-0.12)$, number of persons in the caregiver's social support network $(r=0.13)$, and physical health $(r=0.01)$, indicating that this instrument is assessing something other than social support, mental health, or physical health. This is important given the problem with construct overlap that characterizes many of the measures now being used to assess spirituality [3] [41].

There was also strong evidence for convergent validity, i.e., the extent to which a scale correlates with other measures whose validity has been established by prior work [42]. The BIAC was strongly correlated with intrinsic religiosity $(r=0.77)$ measured using a scale that has been validated against ministers' judgments (see earlier citations). Likewise, the BIAC was strongly correlated with positive aspects of religious support (a potentially 


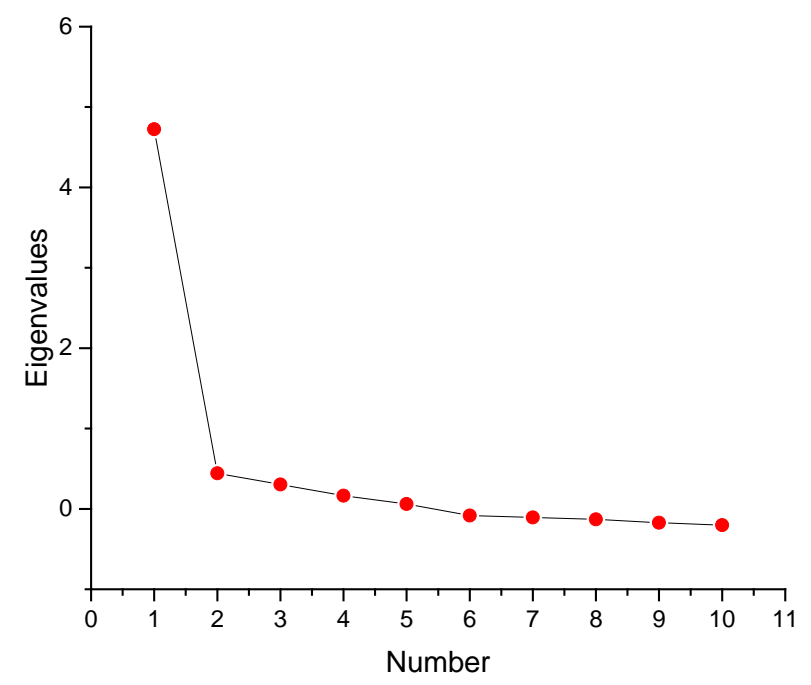

Figure 1. Scree plot of eigenvalues.

key factor in alleviating caregiver stress) with r's ranging from 0.61 to 0.66 . Finally, the average score obtained by those with a religious affiliation was almost four times that of those without an affiliation (47.5 vs. 13.3 ). Scores were also highest in minority groups (Black and Hispanic), which has often been reported using other measures of religiosity [43] [44].

Since the BIAC might be useful in studies examining health outcomes, we also found evidence for predictive validity in that the BIAC was significantly correlated with mental and social health outcomes such as perceived stress $(r=-0.24)$ and satisfaction with support $(r=0.30)$ (and similar correlations, though weaker, were present for caregiver burden and depressive symptoms, as might be expected given the important role that religion could play in buffering caregiver stress).

\section{Limitations}

Besides the strengths noted above, the present study has numerous limitations. First, the sample was one of convenience and all analyses were cross-sectional. Second, the sample was composed of caregivers, so the results should be applied cautiously outside this population. Third, since all participants were female and there are known gender differences in religiosity, the psychometric properties of the BIAC in males remain unknown. Fourth, the scale was designed primarily for members of monotheistic religious traditions, and given the present sample (87\% Christian), the BIAC may not perform as well (or at all) in non-monotheistic traditions. There is even some concern about the usefulness of the scale in those of Jewish or Muslim faith. Although the numbers are small, average scores on the BIAC in Jewish female caregivers $(n=6)$ and Muslim female caregivers $(n=3)$ were quite low, suggesting that further research is needed in larger samples drawn from these faith traditions.

\section{Conclusion}

The BIAC is a reliable and valid scale for comprehensively assessing the central role that religion plays. This study reports the psychometric properties of the BIAC in women caregivers involved in the often stressful task of providing for a loved one with chronic, disabling illness. Given the unique nature of the present sample (middle-aged female caregivers, most of whom were Christian), future research is needed to test the BIAC in other population groups, both community-dwelling and institutionalized (including males), and in those affiliated with Jewish, Muslim, and other monotheistic and non-monotheistic religious traditions [45]. A copy of the BIAC scale for use in research can be obtained at http://www.spiritualityandhealth.duke.edu/index.php/publications/research-publications.

\section{References}

[1] Hill, P.C. and Hood Jr., R.W. (1999) Measures of Religiosity. Religious Education Press, Birmingham. 
[2] King, M., Speck, P. and Thomas, A. (2001) The Royal Free Interview for Spiritual and Religious Beliefs: Development and Validation of a Self-Report Version. Psychological Medicine, 31, 1015-1023. http://dx.doi.org/10.1017/S0033291701004160

[3] Koenig, H.G. (2008) Concerns about Measuring “Spirituality” in Research. The Journal of Nervous and Mental Disease, 196, 349-355. http://dx.doi.org/10.1097/NMD.0b013e31816ff796

[4] Koenig, H.G. and Futterman, A. (1995) Religion and Health Outcomes: A Review and Synthesis of the Literature. Methodological Approaches to the Study of Religion, Aging, and Health. National Institute on Aging, Bethesda, 16-17 March.

[5] Gallagher, D., Rose, J., Rivera, P., Lovett, S. and Thompson, L.W. (1989) Prevalence of Depression in Family Caregivers. Gerontologist, 29, 449-456. http://dx.doi.org/10.1093/geront/29.4.449

[6] Danhauer, S.C., McCann, J.J., Gilley, D.W., Beckett, L.A., Bienias, J.L. and Evans, D.A. (2004) Do Behavioral Disturbances in Persons with Alzheimer's Disease Predict Caregiver Depression over Time? Psychology and Aging, 19, 198-202. http://dx.doi.org/10.1037/0882-7974.19.1.198

[7] Selwood, A., Johnston, K., Katona, C., Lykestsos, C. and Livingston, G. (2007) Systematic Review of the Effect of Psychological Interventions on Family Caregivers of People with Dementia. Journal of Affective Disorders, 101, 7589. http://dx.doi.org/10.1016/j.jad.2006.10.025

[8] Carretero, S., Garces, J., Rodenas, F. and Sanjose, V. (2009) The Informal Caregiver’s Burden of Dependent People: Theory and Empirical Review. Archives of Gerontology and Geriatrics, 49, 74-79. http://dx.doi.org/10.1016/j.archger.2008.05.004

[9] Schulz, R., O’Brien, A.T., Bookwala, J. and Fleissner, K. (1995) Psychiatric and Physical Morbidity Effects of Dementia Caregiving: Prevalence, Correlates, and Causes. Gerontologist, 35, 771-791. http://dx.doi.org/10.1093/geront/35.6.771

[10] Pinquart, M. and Sorensen, S. (2003) Differences between Caregivers and Non-Caregivers in Psychological Health and Physical Health: A Meta-Analysis. Psychology and Aging, 18, 250-267. http://dx.doi.org/10.1037/0882-7974.18.2.250

[11] Lovell, B. and Wetherell, M.A. (2011) The Cost of Caregiving: Endocrine and Immune Implications in Elderly and Non Elderly Caregivers. Neuroscience \& Biobehavioral Reviews, 35, 1342-1352. http://dx.doi.org/10.1016/j.neubiorev.2011.02.007

[12] Pargament, K. (1997) The Psychology of Religion and Coping. Guilford Press, New York.

[13] Koenig, H.G. (2012) Religion, Spirituality and Health: The Research and Clinical Implications. ISRN Psychiatry, 2012, Article ID: 278730. http://dx.doi.org/10.5402/2012/278730

[14] Rabins, P.V., Fitting, M.D., Eastham, J. and Zabora, J. (1990) Emotional Adaptation over Time in Care-Givers for Chronically Ill Elderly People. Age and Ageing, 19, 185-190. http://dx.doi.org/10.1093/ageing/19.3.185

[15] Haley, W.E., Gitlin, L.N., Wisniewski, S.R., Mahoney, D.F., Coon, D.W., Winter, L., Corcoran, M., Schinfeld, S. and Ory, M. (2004) Well-Being, Appraisal, and Coping in African-American and Caucasian Dementia Caregivers: Findings from the REACH Study. Aging \& Mental Health, 8, 316-329. http://dx.doi.org/10.1080/13607860410001728998

[16] Pearce, M.J., Singer, J.L. and Prigerson, H.G. (2006) Religious Coping among Caregivers of Terminally Ill Cancer Patients: Main Effects and Psychosocial Mediators. Journal of Health Psychology, 11, 743-759. http://dx.doi.org/10.1177/1359105306066629

[17] Hebert, R.S., Dang, Q. and Schulz, R. (2007) Religious Beliefs and Practices Are Associated with Better Mental Health in Family Caregivers of Patients with Dementia: Findings from the REACH Study. American Journal of Geriatric Psychiatry, 15, 292-300. http://dx.doi.org/10.1097/01.JGP.0000247160.11769.ab

[18] Brody, E.M. (1981) “Women in the Middle” and Family Help to Older People. Gerontologist, 21, 471-480. http://dx.doi.org/10.1093/geront/21.5.471

[19] Stone, R., Cafferata, G.L. and Sangl, J. (1987) Caregivers of the Frail Elderly: A National Profile. Gerontologist, 27, 616-626. http://dx.doi.org/10.1093/geront/27.5.616

[20] Francis, L.J. (1997) The Psychology of Gender Differences in Religion: A Review of Empirical Research. Religion, 27, 81-96. http://dx.doi.org/10.1006/reli.1996.0066

[21] Cohen, S. and Williamson, G. (1988) Perceived Stress in a Probability Sample of the US. In: Spacapam, S. and Oskamp, S., Eds., The Social Psychology of Health: Claremont Symposium on Applied Social Psychology, Sage, Newbury Park.

[22] Zarit, S.H., Orr, N.K. and Zarit, J.M. (1985) Chapter 4: Understanding the Stress of Caregivers: Planning an Intervention. In: Zarit, S., Ed., The Hidden Victims of Alzheimer's Disease: Families Under Stress, New York University Press, New York.

[23] Radloff, L.S. (1977) The CES-D Scale: A Self-Report Depression Scale for Research in the General Population. Ap- 
plied Psychological Measurement, 1, 385-401. http://dx.doi.org/10.1177/014662167700100306

[24] Fillenbaum, G.G. (1988) Multidimensional Functional Assessment of Older Adults: The Duke Older Americans Resources and Services Procedures. Lawrence Erlbaum Associates, Hillsdale.

[25] Katz, S., Ford, A.B., Moskowitz, R.W., Jackson, B.A. and Jaffe, M.W. (1963) Studies of Illness in the Aged. The Index of ADL: A Standardized Measure of Biological and Psychosocial Function. Journal of the American Medical Association, 185, 914-919. http://dx.doi.org/10.1001/jama.1963.03060120024016

[26] Lawton, M.P. and Brody, E.M. (1969) Assessment of Older People: Self-Maintaining and Instrumental Activities of Daily Living. Gerontologist, 9, 179-186. http://dx.doi.org/10.1093/geront/9.3_Part_1.179

[27] Sarason, I.G., Sarason, B.R., Shearin, E.H. and Pierce, G.R. (1987) A Brief Measure of Social Support: Practical and Theoretical Implications. Journal of Social and Personal Relationships, 4, 497-510. http://dx.doi.org/10.1177/0265407587044007

[28] Hoge, D.R. (1972) A Validated Intrinsic Religious Motivation Scale. Journal for the Scientific Study of Religion, 11, 369-376. http://dx.doi.org/10.2307/1384677

[29] Koenig, H.G., Smiley, M. and Gonzales, J. (1988) Religion, Health, and Aging. Greenwood Press, Westport, 175.

[30] Koenig, H.G., Meador, K.G. and Parkerson, G. (1997) Religion Index for Psychiatric Research. American Journal of Psychiatry, 154, 885-886. http://dx.doi.org/10.1176/ajp.154.6.885b

[31] Krause, N. (1999) Religious Support. In: Multidimensional Measurement of Religiousness/Spirituality for Use in Health Research: A Report of the Fetzer Institute/National Institute on Aging Working Group, Fetzer Institute, Kalamazoo, 57-63.

[32] Pargament, K.I., Smith, B.W., Koenig, H.G. and Perez, L. (1998) Patterns of Positive and Negative Religious Coping with Major Life Stressors. Journal for the Scientific Study of Religion, 37, 710-724.

http://dx.doi.org/10.2307/1388152

[33] Pargament, K.I., Koenig, H.G., Tarakeshwar, N. and Hahn, J. (2001) Religious Struggle as a Predictor of Mortality among Medically Ill Elderly Patients: A Two-Year Longitudinal Study. Archives of Internal Medicine, 161, 1881-1885. http://dx.doi.org/10.1001/archinte.161.15.1881

[34] Ai, A.L., Seymour, E.M., Tice, N., Kronfol, Z., Appel, H. and Bolling, S.F. (2009) Spiritual Struggle Related to Plasma Interleukin-6 Prior to Cardiac Surgery. Psychology of Religion and Spirituality, 1, 112-128. http://dx.doi.org/10.1037/a0015775

[35] Cronbach, L.J. (1951) Coefficient Alpha and the Internal Structure of Tests. Psychometrika, 16, 297-334. http://dx.doi.org/10.1007/BF02310555

[36] Shrout, P.E. and Fleiss, J.L. (1979) Intraclass Correlations: Uses in Assessing Rater Reliability. Psychological Bulletin, 86, 420-428. http://dx.doi.org/10.1037/0033-2909.86.2.420

[37] Kaiser, H.F. (1970) A Second Generation Little Jiffy. Psychometrika, 35, 401-415. http://dx.doi.org/10.1007/BF02291817

[38] Bartlett, M.S. (1954) A Further Note on the Multiplying Factors for Various $X^{2}$ Approximations in Factor Analysis. Journal of the Royal Statistical Society, 16, 296-298.

[39] Kaiser, H.F. (1991) Coefficient Alpha for a Principal Component and the Kaiser-Guttman Rule. Psychological Reports, 68, 855-858. http://dx.doi.org/10.2466/pr0.1991.68.3.855

[40] Campell, D.T. and Fiske, D.W. (1959) Convergent and Discriminant Validation by the Multitrait-Multimethod Matrix. Psychological Bulletin, 56, 81-105. http://dx.doi.org/10.1037/h0046016

[41] Tsuang, M.T. and Simpson, J.C. (2008) Commentary on Koenig (2008): Concerns about Measuring "Spirituality” in Research. Journal of Nervous \& Mental Disease, 196, 647-649. http://dx.doi.org/10.1097/NMD.0b013e3181813570

[42] Messick, S. (1995) Validity of Psychological Assessment: Validation of Inferences from Persons’ Responses and Performances as Scientific Inquiry into Score Meaning. American Psychologist, 50, 741-749. http://dx.doi.org/10.1037/0003-066X.50.9.741

[43] Johnson, G.D. and Matre, M. (1991) Race and Religiosity: An Empirical Evaluation of a Causal Model. Review of Religious Research, 32, 252-268. http://dx.doi.org/10.2307/3511210

[44] Levin, J.S., Taylor, R.J. and Chatters, L.M. (1994) Race and Gender Differences in Religiosity among Older Adults: Findings from Four National Surveys. Journal of Gerontology, 49, S137-S145. http://dx.doi.org/10.1093/geronj/49.3.S137

[45] Wang, Z., Ma, H., Rong, Y. and Koenig, H.G. (2015) Psychometric Properties of Belief into Action Scale among University Students in China. Journal for the Scientific Study of Religion, in Submission. 
Scientific Research Publishing (SCIRP) is one of the largest Open Access journal publishers. It is currently publishing more than 200 open access, online, peer-reviewed journals covering a wide range of academic disciplines. SCIRP serves the worldwide academic communities and contributes to the progress and application of science with its publication.

Other selected journals from SCIRP are listed as below. Submit your manuscript to us via either submit@scirp.org or Online Submission Portal.
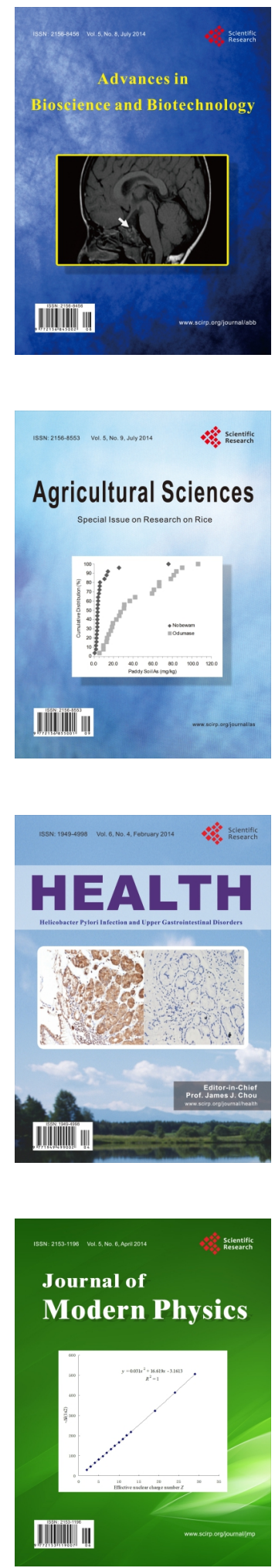
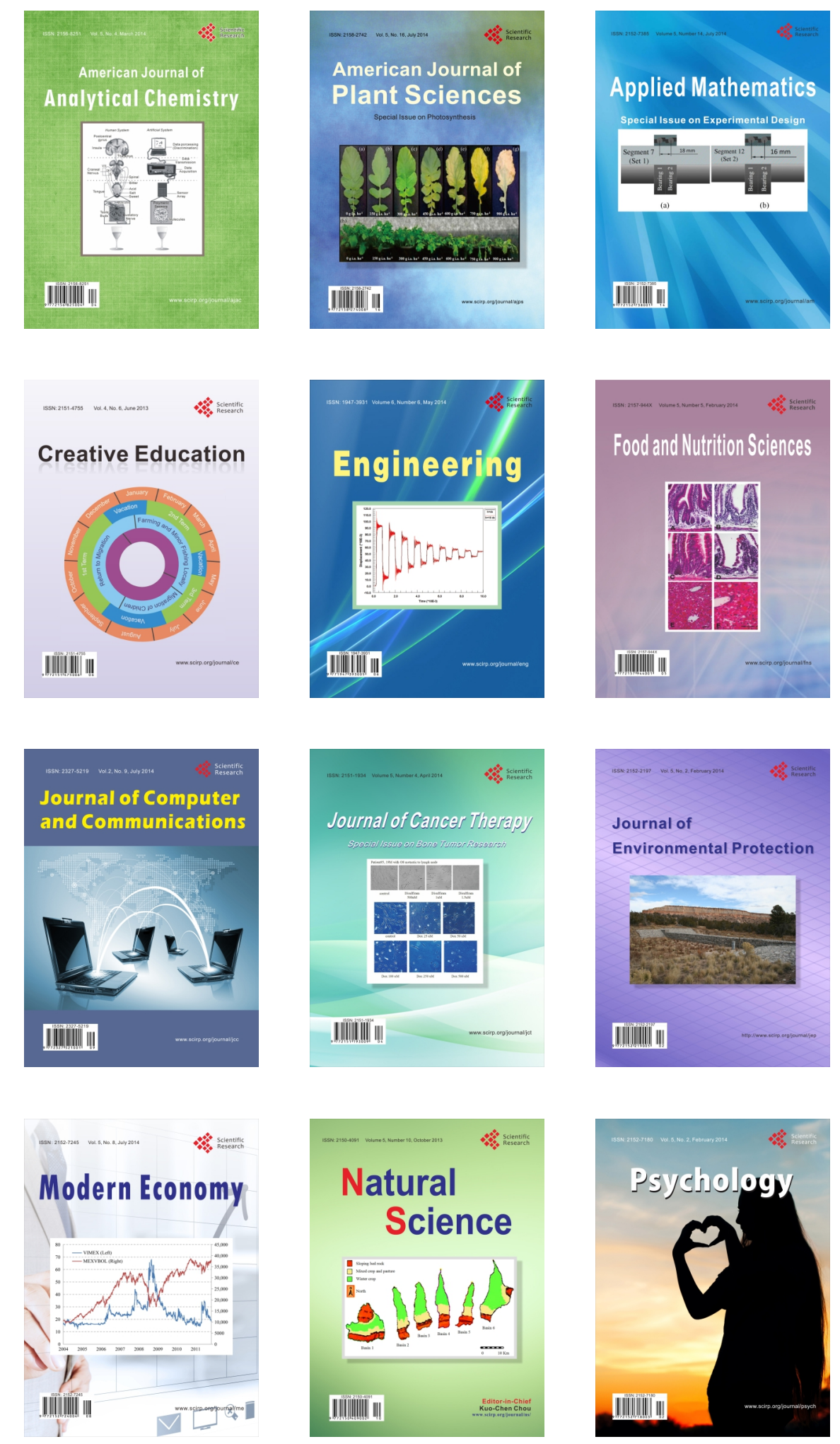